\title{
Representation of corruption in Vietnam's contemporary mass media: insights from satirical cartoons
}

\author{
Ho Manh Tung ${ }^{1,2,3}$ \\ ${ }^{1}$ Ritsumeikan Asia Pacific University, Beppu, Oita Prefecture, 874-8577, Japan \\ ${ }^{2}$ Vietnam Academy of Social Sciences, Institute of Philosophy, Lang Ha, Ba Dinh, Hanoi, \\ 100000, Vietnam \\ ${ }^{3}$ Centre for Interdisciplinary social research, Phenikaa University, Yen Nghia, Ha Dong, Hanoi, \\ 100803, Vietnam
}

This version: v.1, February 2, 2019

Beppu, Oita 874-8577, Japan

"The inversions, reversals, subversions, the breaking of rules and crossing of invisible lines that characterize humorous phenomena may have some universal shapes and shifts, but they remain intimately and often elusively localized in their nuance and content." Carty \& Musharbash (2008)

This article analyzes the contemporary representation of the corruption in Vietnam's popular media, taking the local news outlet of Tuoi Tre Cuoi (Youth Humor) as the sole source of data. This article is divided into three sections. The first section deals with the brief history of political cartoon in Vietnam. The second section gives the background of Tuoi Tre Cuoi and why it provides a fruitful setting for this investigation. The third section presents an analysis of the content and form of the representation of corruption, upon which the traces of historical development in the practice of political cartoon will be explored. Finally, the paper suggests the practice of political cartoon in Vietnam has provided an important venue for political reflection and entertainment on a daily basis for the Vietnamese people, whether or not it is essentially about political engagement. 


\section{A brief history of political cartoon in Vietnam}

The earliest forms of cartooning in Vietnam can be found in the woodblock reproduction of traditional drawings (Phan, 2003). These drawings depict the life of the ordinary people in traditional villages of Vietnam. Many of the drawings are highly satirical in nature. For example, in the more traditional popular drawings, the animals in human roles are regularly used to lampoon and satirize foolish and hypocritical behaviors. The arrogant people are often depicted as the toad, the oppressive village officials as the cat, the poor and the oppressed as the mouse (Phan, 2003). As Vietnam became a colony of France in the $19^{\text {th }}$ century to the mid- $20^{\text {th }}$ century, the intellectuals in this period started to mix the traditional satire with the Western forms of humor including cartoons. Driven by the desire to increase sales, by 1930s, newspapers had increasingly used jokes, cartoons, and humorous stories, making this an established practice. The subject for the jokes was outdated social and religious practices and of course, the colonial rulers and their puppet royal courts (Lent, 2014; Phan, 2003). As the French government in Vietnam at the time began to crack down on satirists and intensify censorship, the explicit caricatures gave way to a more symbolic representation - the artists turned to symbols rooted from the folk songs, verses, and literature. For example, people with pot-belly and barefoot often represent backwardness and ignorance of the rural residents; obese men dressed in government uniform or mandarin robe represent the greediness and corruption in the political system. During the 30 years of wartime, from 1945-1975, cartooning in North Vietnam focused on the war efforts, some famous artists such as Si Ngoc, Bui Xuan Phai, Huy Toan, etc. all published their illustrations in state-owned newspapers (Le-Thuy, 2011; Lent, 2014). While in the South, the practice continued to flourish with the success of one of the most famous satirical artists in Vietnam, Nguyen Hai Chi. His works were even featured in the New York Times, Asahi Shinbun, and Newsweek (Lent, 2014; Phan, 2003). After the unification in 1975, political cartoons did not fare well until after Vietnam opened to the world in 1986. Lent (2014) suggested that the combining force of the political environment, as well as the hard economic reality of the time, was perhaps behind the lack of development in cartooning.

For the past 30 years, thanks to gradual economic reforms and an open-door policy, Vietnam has enjoyed continual rapid economic growth, consistently recording a gross domestic product (GDP) growth rate of over 6\% in the recent five years (Vuong, 2019; Vuong, 2014). Vietnam has become one of the most globalized countries in the world and has signed bilateral free trade agreements with many major economies including China, Japan, Korea, India, etc. (Kopf, 2018). The economic transformation has undoubtedly carried important implications for the practice of political cartoon in the country. Unlike during the wartime when people struggled to stay alive and fend for their families, the newfound prosperity has given the Vietnamese more time to catch up with the daily news, including trending satirical cartoons. To meet this growing 
demand for news content, most newspapers and magazines now have their online sites and released illustrations and cartoons daily.

Moreover, with the rise of social media, all newspapers have launched their Facebook sites which interact with the audience on a daily basis (Nguyen, 2012). Compared with only ten years ago when cartoons only appeared weekly in major newspapers such as Nhan Dan, Thanh Nien, and Tuoi Tre (Lent, 2014), now cartoons have become a daily production. Another important change in the age of the Internet and social media is that the major news outlets have started to use the cartoons drawn by their readers more frequently, while just nearly eight years ago, most of them only used the drawings of their in-house artists.

\section{Research question}

The following question will serve as the focal point of this investigation:

What are the major characteristics in the representation of corruption in Vietnam's contemporary mass media?

\section{Materials and methods}

This study analyzes the changes in the contemporary representation of corruption in political cartoons in Tuoi Tre Cuoi (Youth Humor), the magazine that has been operating at the frontier of using satirical cartoons for political and social critiques. According to John A. Lent (2014), Tuoi Tre Cuoi is an important venue for cartoonists in Vietnam given the absence of a journalistic tradition, centuries of mandarin bureaucracy and one hundred years of colonial censorship. It is a magazine subdivision of Tuoi Tre (Youth), one of the most widely read newspapers in Vietnam, founded in 1975 as a mouthpiece of the Ho Chi Minh branch of the Communist Youth Union (Nguyen, 2012).

The paper's daily print circulation reached about 400,000 in 2010 (McKinley, 2011), a figure that has not been updated since. Tuoi Tre Cuoi is filled with satirical cartoons, illustrated jokes, and caricatures. The magazine has become so popular that Keenan (1997, cited by Lent, 2014) suggested that it was setting the agenda for modern satire in Vietnam. In recent years, with the penetration of the Internet and the rise of social media (Abuza, 2015; Hayton, 2010), Tuoi Tre Cuoi, as with other news outlets, launched its Facebook homepage in 2015 and now enjoyed the readership of 550,000 followers. With such an important role in the practice of political cartoon in Vietnam, Tuoi Tre Cuoi is a well-suited source of data for this study.

Regarding analytical framework, this essay draws heavily from the Scott (2007)'s work on a comparison of comic book propaganda from World War II to September 11. 


\section{Characteristics of Vietnamese political cartoons}

\section{Taboos}

Phan (2003) observed there is a major difference between the political cartoons in the West and Vietnam. While in Western countries, high-profile politicians and other public figures are often depicted in the cartoons in very unflattering manners, in Vietnam, it is a taboo for cartoonists to do so. Caricatures of Vietnamese national leaders were almost non-existent. However, the author noted the increased freedom had allowed the cartoonists to take this taboo and subjected it to satirical depiction as well. For example, in 1999, in Tuoi Tre Cuoi, there was a cartoon where the editor of a newspaper pointed to the portraits of the national leaders and famous people on the wall and reminded the artist not to depict them too realistically (Figure 1).

Figure 1: Tuoi Tre Cuoi, no. 185, June 1999 as cited by (Phan, 2003). The editor of a newspaper points at the portraits of famous people on the wall and remind his artists not to draw them realistically.

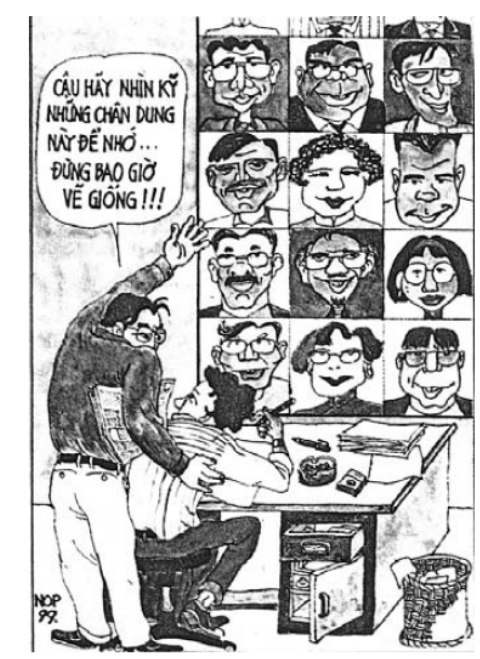

The author also remarked in cases where the government officials are convicted, and these restrictions are removed. However, surveying the cartoons published by Tuoi Tre Cuoi over the past three years, during which the anti-corruption campaign of the government has intensified, and several high-profile national leaders have been arrested, this study has not found any example of the realistic depiction of the government officials. It seems that the liberal sentiment represented in 1999 (Figure 1) has never become mainstream.

\section{The use of auxiliary markers}

As seen in Figure 1, the cartoon employs the speech balloon which says: "You must remember these faces and your drawings must never resemble them.” This seems to be a general tendency of political cartoon in Vietnam. The artists tend to employ auxiliary markers and verbal 
cues to guide the readers toward their authorial intent, avoiding erroneous interpretations. It seems this tendency has not changed until now. Figure 2 and the subsequent figures are very clear examples. As can be seen in Figure 2, the satirical cartoon presents the "Road to the peak of corruption" reality show. In the picture, the government official who is in charge of failed projects that are together worth VND12 trillion (USD517 million) (perhaps it refers to the 12 failed national projects of the Ministry of Trade and Finance, each is worth trillions of dong (LDO, 2017)) wins the prize. To interpret this cartoon, it is clear that the verbal cues are helpful.

Figure 2: Tuoi Tre Cuoi, 2017 December 19. The figure presents perhaps a reality show called "Road to the peak of corruption," in which the contestants present their failed (national) projects.

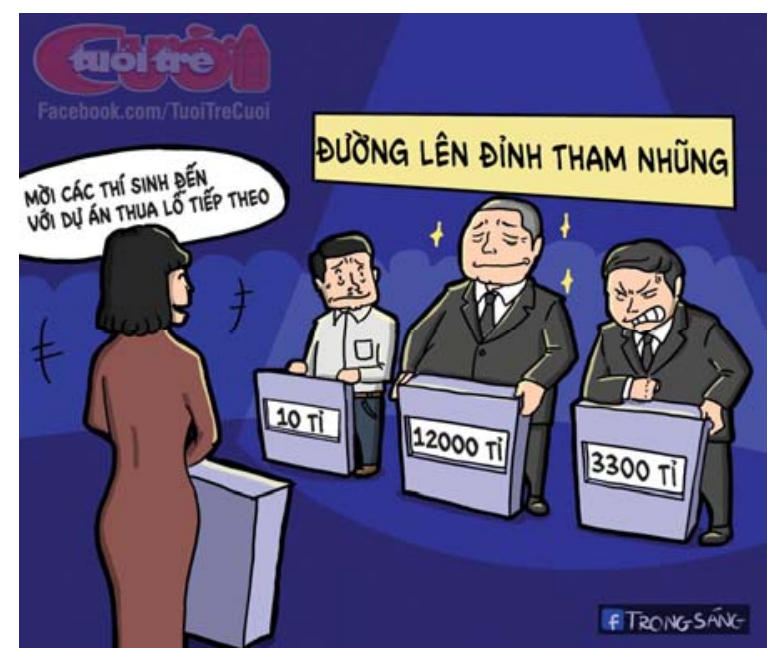

The tendency toward using auxiliary markers is often analyzed within the classification of cartoon audiences into low-brow and high-brow categories. The audiences with less education who might need more verbal cues and symbols are categorized as low-brow, while the more educated audiences are categorized as high-brow (Alba, 1967). In the case of Tuoi Tre Cuoi, the magazine caters to the widest possible audience. Thus, it might be the case that most of their intended audience would need the verbal cues to make sense of the cartoons. However, it can also be the fact that the strict political environment in Vietnam forces the artists not to take the risk to let the audience infer the meaning of their cartoons too liberally. It is important to remember that Tuoi Tre Cuoi, after all, is a state-owned enterprise.

Figure 3: Tuoi Tre Cuoi, 2018 November 8. The figure presents the illusion of punishment within the political system. An official is punished and get demoted, yet somehow after that, he arrives at a higher position. 


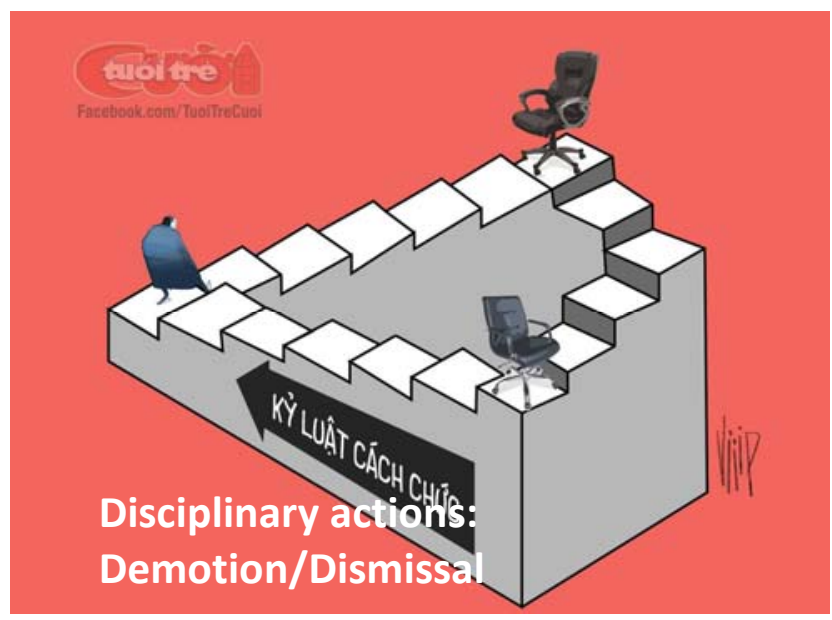

\section{Representation of stereotypes}

Concerning stereotypical representations in Vietnam's political cartoon, the most prevalent is the stereotype of the greedy, corrupt government official. In Figures 2, 3 and 4, the corrupt government officials are drawn with a big, fat belly. In fact, in Figure 2, the more corrupt an official is, the fatter and bigger he looks. In many cases, the government officials are also referred to as a mandarin of a royal court ("quan" in Vietnamese). Figure 4 presents a satirical cartoon on the problem of nepotism, in which the government official is referred to using the language of a royal court.

Figure 4. Tuoi Tre Cuoi, 2018 December 19. A government official takes his son to a fortuneteller. The fortune-teller says it doesn't matter which Chinese Zodiac sign he is; he is always the son of a "mandarin."

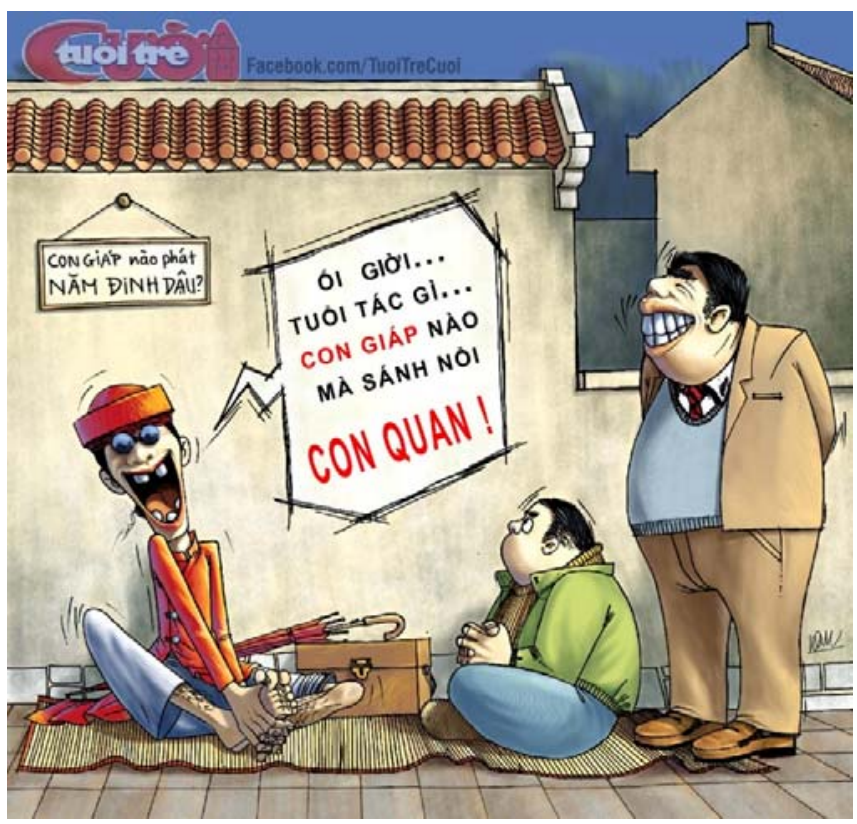


The depiction of the greedy corrupted mandarin/official as a big, fat person is wellestablished in Vietnamese culture (Phan, 2003). However, some important changes should be noted. In the past, as Phan (2003) pointed out, the backward and ignorant poor persons are often depicted as rats. Nowadays, the corrupt officials are the like of rats digging holes and eating from the national budget (Figure 5).

Figure 5: Tuoi Tre Cuoi, 2018 November 12. The picture depicts the corrupted officials as rats digging holes and eating from the national budget.

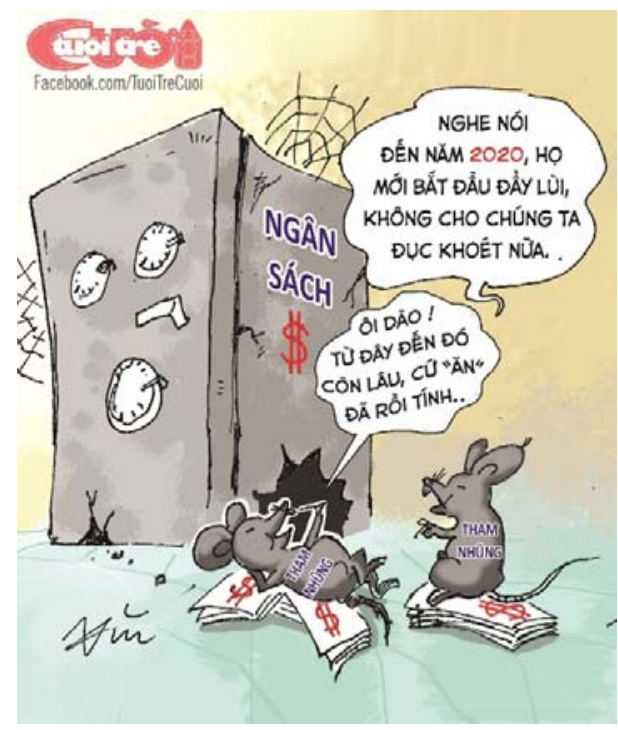

The corrupt officials are also likened to the images of insects, which appear to be small and harmless but in reality cause all sorts of problems (Figure 6). The reference could be drawn from Vietnamese cultures, in which many well-known idioms about insects are often derogatory or pejorative. One instance is the phrase: "Con sâu làm rầu nồi canh" which translates to "one worm ruins the whole pot."

Figure 6: Tuoi Tre Cuoi, 2019 January 1. Corrupt officials are depicted as insects.

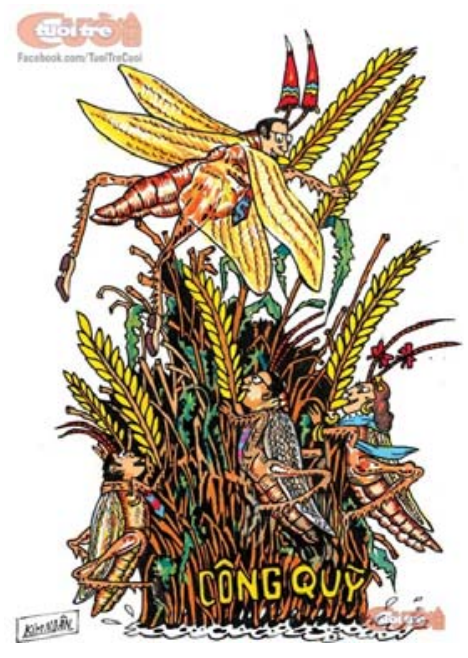


The willingness to represent corruption as a systemic problem

A notable development in Vietnamese political cartoon is the willingness to depict corruption as a systemic problem. Phan (2003) argues that political cartoon in Vietnam tends toward showing corruption is the result of only a few greedy and immoral behaviors as this is the position of the ruling party as well. However, in recent years, there seem to be more cartoons depicting this problem as systemic. Figures 7 and 8 are very clear examples. In Figure 7, the dad and the son are having a conversation. The son asks the dad why the bald and fat person is so rich. The dad tells him he is rich because his subordinates bribe him, and the subordinates take a bribe from his staffs. Somewhere along the line, the normal vendors have to bribe some government officials, which eventually leads to higher prices of goods. In most of the conversation, the father assures his son that there is no connection to their life, but when it comes to the hike of commodity prices, the father admits to the son he is wrong.

Figure 7: Tuoi Tre Cuoi, 2017 December 19. Depiction of systemic corruption.

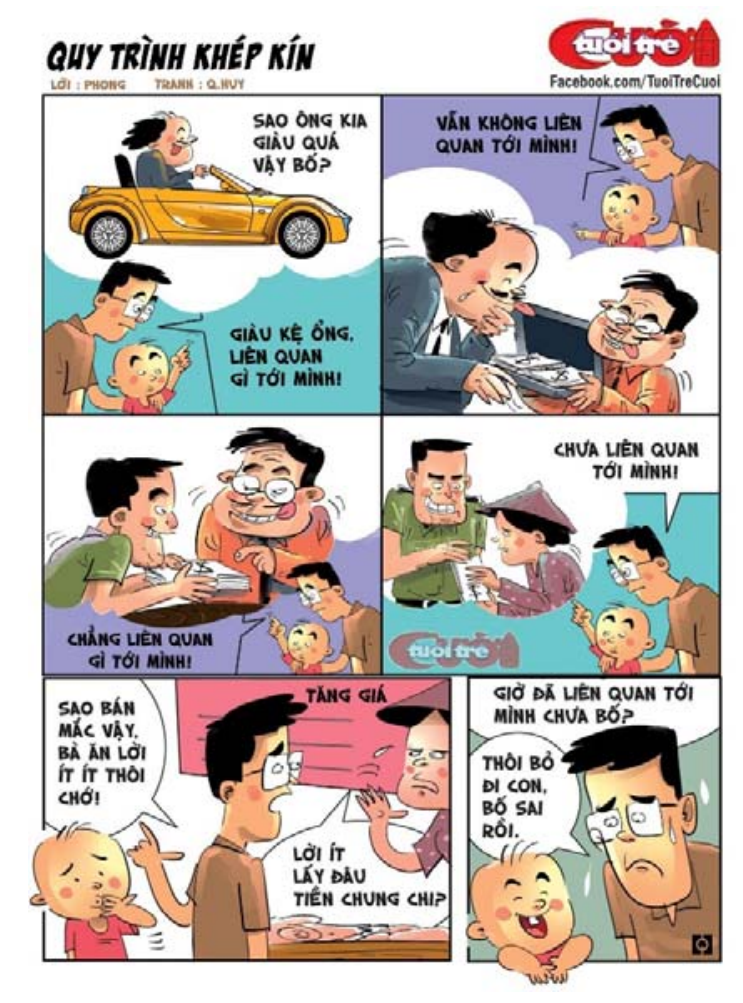

Figure 8 below depicts the corruption in education as a systemic problem, in which pressure for achievements from high-up the chain of command makes people within the hierarchy pushes each other, leading to the incident of a teacher hitting her students.

Figure 8: Tuoi Tre Cuoi, 2018 December 1. The depiction of corruption in education as a systemic problem. 


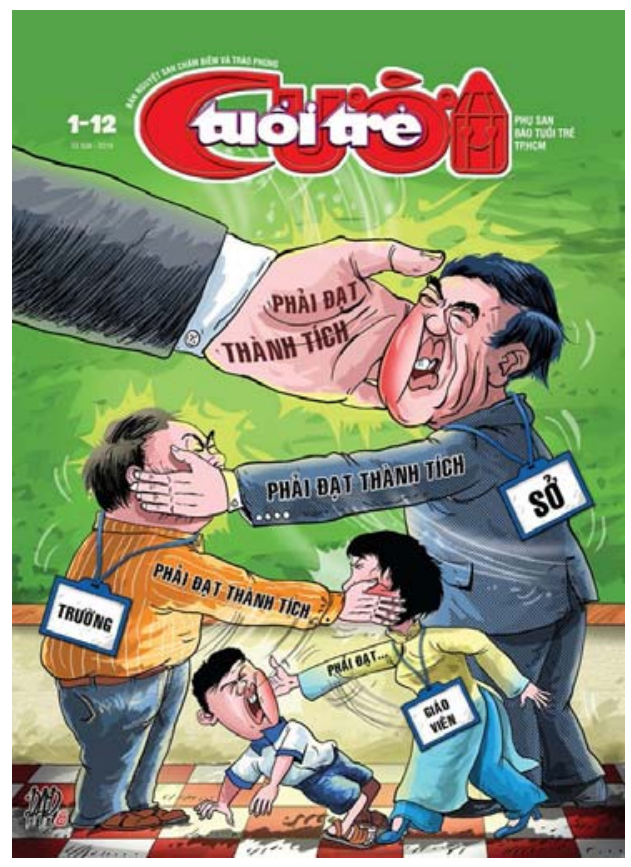

It is not clear whether or not the ruling party has changed their position on the problem of corruption. However, it is clear that the ruling party has intensified the quest to root out corrupt members (Hung, 2018), resulting in the prosecutions of many high-profile politicians. Moreover, the party has always acknowledged the problem of corruption is rampant within the at all levels of governance. Perhaps, under this environment, the artists have found themselves greater freedom. Another explanation for this observation might be the sensibility of the audience has changed. As Vietnam becomes more embedded in the global economy, the country's young, tech- and mediasavvy population (Minh-Nga, 2018) is more likely to enjoy a more nuanced depiction of corruption.

\section{Discussion and conclusion}

This article has presented a brief analysis of the representation of corruption in Vietnam's political cartoon. Using the examples from a popular state-owned satirical magazine, this article shows that the representation of corruption in Vietnam's contemporary mass media exhibits some continuity with its traditional historical characteristics. For example, it is still a taboo to depict high-profile politicians too realistically, though this taboo has once been a subject of satire.

This is perhaps a result of the conservative Confucian heritage which has been a dominant force in Vietnamese culture (Vuong et al., 2018; Vuong \& Tran, 2009). In this tradition, the issue of the "face" is almost a sacred value (Han, 2016). The heavy use of auxiliary markers and verbal cues to guide and interpret the meaning of satirical cartoons remains unchanged, which indicate that the strict political and media environment in Vietnam makes the artists unwilling to take risks to let the audiences interpret the meaning freely. 
Regarding the stereotypical representation of the corrupt official, the analysis shows that the artists continue to refer many traditional elements of Vietnamese cultures such as idioms, folk songs, and folk literature. A notable change is the image of the rat is reserved for the corrupt officials, while in the past it is the poor and backward persons that were likened to the rats. Another important change is that there seems to be a greater willingness to depict corruption as a systemic problem. This stands in the opposition with the observation made by Phan (2003) that corruption in Vietnam tends to be depicted as the problem of only a few dishonest and greedy people. Though, this change might not reflect the change in the political orientation of the country, yet, it does hints at a change in the sensibility of the audience as well as a more open media environment that tolerates straightforward discussion of corruption.

Overall, the investigation of the representation of corruption in a contemporary political cartoon in Vietnam does resonate the observation of McAllister and Luckman (2015). They analyze the case of the popular 15-years-old satirical TV show called Tao Quan (The Kitchen Gods): the show has fulfilled its two-fold task-entertaining a large audience and offering a critical reflection on the life of the nation. Whether or not Vietnam's contemporary political satirical cartoon can be considered a form of political engagement is a debatable subject (Yang \& Jiang, 2015), it is clear that the practice has provided a venue for political entertainment and reflection on a daily basis for the Vietnamese people.

\section{Acknowledgments}

The author would like to express the deepest gratitude toward Prof. Vuong Quan Hoang for pointing out this research direction; Prof. Joseph Progler for excellent advice and continued support during the research process; and Prof. Yoshida Kaori for suggesting a suitable analytical framework.

\section{References}

Abuza, Z. (2015). Stifling the public sphere: Media and civil society in Vietnam. Retrieved from International Forum for Democratic Studies: http://www.ned.org/wpcontent/uploads/2015/10/Stifling-the-Public-Sphere-Media-Civil-Society-Egypt-RussiaVietnam-Full-Report-Forum-NED.pdf\#page $=37$

Alba, V. (1967). The Mexican Revolution and the cartoon. Comparative Studies in Society and History, 9(2), 121-136.

Carty, J., \& Musharbash, Y. (2008). You've Got to be Joking: Asserting the Analytical Value of Humour and Laughter in Contemporary Anthropology AU - Carty, John. Anthropological Forum, 18(3), 209-217. doi:10.1080/00664670802429347 
Han, K.-H. (2016). The feeling of "Face" in Confucian society: from a perspective of psychosocial equilibrium. Frontiers in psychology, 7, 1055.

doi:10.3389/fpsyg.2016.01055

Hayton, B. (2010). Vietnam: rising dragon. New Haven: Yale University Press.

Hung, N. M. (2018). VIETNAM IN 2017: Power Consolidation, Domestic Reforms, and Coping with New Geopolitical Challenges. Southeast Asian Affairs, 2018(1), 407-428.

Kopf, D. (2018). Vietnam is the most globalized populous country in modern history. Retrieved from https://www.weforum.org/agenda/2018/10/vietnam-is-the-most-globalizedpopulous-country-in-modern-history/

LDO. (2017). Infographic: Điểm mặt 12 dự án thua lỗ nghìn tỉ của Bộ Công thương [Infographic: Take a look at the 12 failed projects, each worth a thousand billion VND, of the Ministry of Industry and Finance]. Retrieved from https://laodong.vn/video-thoi-su/infographicdiem-mat-12-du-an-thua-lo-nghin-ti-cua-bo-cong-thuong-680093.bld

Le-Thuy. (2011). Thăng trầm biếm họa Việt Nam [The up and down of satirical cartoon in Vietnam]. Retrieved from http://daibieunhandan.vn/default.aspx?tabid=78\&NewsId=206903

Lent, J. A. (2014). Cartooning in Vietnam: A brief overview. In J. A. Lent (Ed.), Southeast Asian cartoon art: History, trends, and problems (pp. 122-139). Jefferson, North Carolina: McFarland.

McAllister, P., \& Luckman, T. C. T. (2015). The Kitchen God Returns to Heaven [Ông Táo Về Trời]: Popular Culture, Social Knowledge and Folk Beliefs in Vietnam. Journal of Vietnamese Studies, 10(1), 110-150.

McKinley, C. (2011). Vietnam. In A. Heslop (Ed.), Financially viable media in emerging and developing markets: World Association of Newspapers and News Publishers. Retrieved from http://www.wanifra.org/sites/default/files/field_article_file/Financial_Viability_Report_WAN-IFRA.pdf.

Minh-Nga. (2018). Half of Vietnamese get news from social media, survey finds. Retrieved from https://e.vnexpress.net/news/business/data-speaks/half-of-vietnamese-get-news-fromsocial-media-survey-finds-3698212.html

Nguyen, T. B. (2012). Social media as a marketing channel for traditional newspapers: case: Tuoi Tre Newspaper. (Bachelor), Lahti University of Applied Sciences, Lahti, Finland.

Phan, T. T. (2003). Speaking pictures: Biem hoa or satirical cartoons on government corruption and popular political thought in contemporary Vietnam. In L. B. W. Drummond \& M. Thomas (Eds.), Consuming Urban Culture in Contemporary Vietnam: Routledge Curzon. Scott, C. (2007). Written in red, white, and blue: A comparison of comic book propaganda from World War II and September 11. The Journal of Popular Culture, 40(2), 325-343. 
Vuong, Q.-H., Bui, Q.-K., La, V.-P., Vuong, T.-T., Nguyen, V.-H. T., Ho, M.-T., . . Ho, M.-T. (2018). Cultural additivity: behavioural insights from the interaction of Confucianism, Buddhism, and Taoism in folktales. Palgrave Communications, 4(1), 143. doi:10.1057/s41599-018-0189-2

Vuong, Q. (2019). The financial economy of Viet Nam in an age of reform, 1986-2016. In P. M. a. N. Y. U. Volz (Ed.), Routledge Handbook of Banking and Finance in Asia (pp. 201-222). London, UK: Routledge.

Vuong, Q. H. (2014). Vietnam's political economy: a discussion on the 1986-2016 period. WPCEB $N^{\circ} 14-010$ Universite Libre de Bruxelles.

Vuong, Q. H., \& Tran, T. D. (2009). The cultural dimensions of the Vietnamese private entrepreneurship. IUP Journal of Entrepreneurship Development, VI(3-4), 54-78.

Yang, G., \& Jiang, M. (2015). The networked practice of online political satire in China: Between ritual and resistance. International Communication Gazette, 77(3), 215-231. 